This item was submitted to Loughborough's Research Repository by the author.

Items in Figshare are protected by copyright, with all rights reserved, unless otherwise indicated.

\title{
Systemic accident analysis: examining the gap between research and practice
}

PLEASE CITE THE PUBLISHED VERSION

http://dx.doi.org/10.1016/j.aap.2013.02.041

PUBLISHER

(C) Elsevier

VERSION

AM (Accepted Manuscript)

LICENCE

CC BY-NC-ND 4.0

\section{REPOSITORY RECORD}

Underwood, Peter, and Patrick Waterson. 2019. "Systemic Accident Analysis: Examining the Gap Between Research and Practice". figshare. https://hdl.handle.net/2134/13861. 
This item was submitted to Loughborough's Institutional Repository (https://dspace.lboro.ac.uk/) by the author and is made available under the following Creative Commons Licence conditions.

\section{creative
commons}

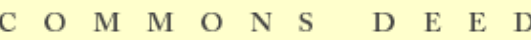

Attribution-NonCommercial-NoDerivs 2.5

You are free:

- to copy, distribute, display, and perform the work

Under the following conditions:

Attribution. You must attribute the work in the manner specified b the author or licensor.

Noncommercial. You may not use this work for commercial purposes.

No Derivative Works. You may not alter, transform, or build upon this work.

- For any reuse or distribution, you must make clear to others the license terms of this work.

- Any of these conditions can be waived if you get permission from the copyright holder.

Your fair use and other rights are in no way affected by the above.

This is a human-readable summary of the Leqal Code (the full license).

\section{Disclaimer 만}

For the full text of this licence, please go to: http://creativecommons.org/licenses/by-nc-nd/2.5/ 
Underwood, P. and Waterson, P., 2013a. Systemic accident analysis: Examining the gap between research and practice. Accident Analysis \& Prevention, 55, pp.154-164.

\title{
Systemic accident analysis: Examining the gap between research and practice
} http://www.sciencedirect.com/science/article/pii/S0001457513000985

Keywords: Accident analysis, Systems approach, Research-practice gap, STAMP FRAM, AcciMap

\begin{abstract}
The systems approach is arguably the dominant concept within accident analysis research. Viewing accidents as a result of uncontrolled system interactions, it forms the theoretical basis of various systemic accident analysis (SAA) models and methods. Despite the proposed benefits of SAA, such as an improved description of accident causation, evidence within the scientific literature suggests that these techniques are not being used in practice and that a research-practice gap exists. The aim of this study was to explore the issues stemming from research and practice which could hinder the awareness, adoption and usage of SAA. To achieve this, semi-structured interviews were conducted with 42 safety experts from ten countries and a variety of industries, including rail, aviation and maritime. This study suggests that the research-practice gap should be closed and efforts to bridge the gap should focus on ensuring that systemic methods meet the needs of practitioners and improving the communication of SAA research.
\end{abstract}

\section{Introduction}

The systems approach is arguably the dominant paradigm in accident analysis and human factors research (e.g. Salmon et al., 2012a; Stanton et al., 2012). It views socio-technical system accidents as the result of unexpected, uncontrolled relationships between a system's constituent parts. This requires the study of systems as whole entities, rather than considering their parts in isolation. Many complex system accidents, e.g. space shuttle Columbia and Comair flight 5191, have not simply resulted from catastrophic equipment failure or an unsafe human action, as required according to traditional cause-effect accident models; instead accidents emerge as complex phenomena within the normal operational variability of 
a system (de Carvalho, 2011). Therefore, describing accidents in a sequential (cause-effect) fashion is arguably inadequate, as it is unable to sufficiently explain the non-linear complexity of modern-day socio-technical system accidents (Hollnagel, 2004; Lindberg et al., 2010). It can also lead to equipment or humans at the 'sharp end' of a system being incorrectly blamed for an accident. This represents a missed opportunity to learn important lessons about system safety and, therefore, develop more effective safety recommendations. Use of the systems approach, via systemic accident analysis (SAA), supposedly avoids these limitations and it has been used as the conceptual foundation for various SAA methods and models, e.g. Systems Theoretic Accident Modelling and Processes model (STAMP) (Leveson, 2004), the Functional Resonance Analysis Method (FRAM) (Hollnagel, 2004) and Accimap (Rasmussen, 1997).

\subsection{Systemic accident analysis in research}

A number of studies have compared SAA methods with established non-systemic analysis techniques, such as Fault Tree Analysis (e.g. Belmonte et al., 2011) and the Sequentially Timed Events Plotting method (e.g. Herrera and Woltjer, 2010). These studies and others like them (e.g. Ferjencik, 2011) suggest that, whilst the nonsystemic methods are suitable for describing what happened in an accident, the SAA techniques provide a deeper understanding of how dynamic, complex system behaviour contributed to the event.

Furthermore, Leveson (2011, p. 349) comments that most accident reports are written from the perspective of cause-effect models and that the analysis frequently stops prematurely. Some studies exemplify this by stating that additional insights were achieved using SAA methods, when compared with the findings of official investigation reports (e.g. Jenkins et al., 2010; Johnson and de Almeida, 2008). The improved understanding of accident causation provided by SAA should, therefore, allow the development of more effective safety recommendations.

\subsection{Systemic accident analysis in practice}

Despite the proposed advantages of SAA, there is evidence within the scientific literature to suggest that methods and tools employing a systemic perspective are not being adopted in practice. For example, some researchers (e.g. Carhart and Yearworth, 2010; Leveson, 2011) comment that the most widely used accident 
analysis tools are based on sequential, reductionist models of systems and causality. Other researchers also suggest that SAA techniques are yet to gain acceptance outside of the research community (e.g. Okstad et al., 2012; Salmon et al., 2012a). These observations are supported by the sequential understanding of accident causation presented within various elements of the practitioner-focused safety literature (e.g. Energy Institute, 2008; Health and Safety Executive, 2004; Rail Safety Standards Board, 2011).

\subsection{The gap between research and practice}

The different analysis approaches taken by the researcher and practitioner communities suggest that a research-practice gap exists in the domain of SAA. Various aspects of the research-practice gap in accident analysis have been previously studied, both from a general perspective and within the context of SAA. Generic factors which can influence a practitioner's approach to accident analysis have been identified, such as investigator bias and resource constraints (e.g. Johnson, 2003; Lundberg et al., 2010). These influences can arguably lead practitioners away from the theoretical ideal of accident investigation and therefore contribute to a research-practice gap (Lundberg et al., 2010). Other studies (e.g. Salmon et al., 2012a; Underwood and Waterson, 2012) have examined how the characteristics of several systemic analysis models impact on the ability of an individual to successfully perform SAA, such as the lack of method reliability caused by their qualitative nature.

Despite the presence of such a research-practice gap there is evidence to suggest that a desire to adopt SAA exists within sections of the practitioner community. For example, accident investigators within aviation have begun to recognise the need to look beyond sequential analysis methods (e.g. Martinez, 2011, p. 8). Further-more, Steele and Pariès (2006) suggest that many practitioners acknowledge the limitations of traditional models and are keen to apply new techniques. Given that a demand to apply SAA seems to exist in both the researcher and practitioner communities, the research-practice gap needs to be examined in more depth.

\subsection{Study aims}

Whilst some of the research-based factors contributing to the SAA research-practice gap have been identified in previous studies (e.g. Underwood and Waterson, 2012), 
it is believed that practitioner-related influences, such as those described by Lundberg et al. (2010), require further examination within the context of SAA. Therefore, the following aims for the study were established:

- Understand how the awareness of, and need for, SAA within the practitioner community could inhibit the adoption and use of SAA.

- Understand how the factors influencing current analysis approaches may hinder the adoption and use of SAA.

- Follow up and probe deeper into the issues stemming from research which may impede the diffusion of SAA into practice.

\section{Methods}

The use of semi-structured interviews was selected as the most appropriate method to achieve the aims of the study for a number of reasons. Firstly, the lack of information regarding SAA within the practitioner literature prevented the use of document analysis alone. Secondly, previous studies focused on the SAA researchpractice gap have used methods such as thematic analysis of the scientific literature (e.g. Underwood and Waterson, 2012) and user evaluations of SAA methods (e.g. Salmon et al., 2012a). Consequentially, interview data was viewed as the most suitable form of information to supplement the existing findings. Finally, semistructured interviews provide the ability to examine topics of interest in varying degrees of depth; an approach which suited the exploratory nature of this study (Robson, 2002).

\subsection{Sampling strategy}

Due to the study resource constraints, it was not possible to create a statistically representative sample. Therefore a convenience sample, considered to be indicative of the accident investigation community, was created. The sample included participants employed as full-time accident investigators, health and safety professionals (e.g. company safety managers), human factors specialists and accident analysis researchers. However, these participant categories were not mutually exclusive, e.g. some practitioners had research experience. Therefore, participants were allocated to the category associated with their current role as it was felt that their role would have the most influence on their analysis approach, e.g. due 
to resource constraints. Also, gaining a detailed understanding of how a participant's background influenced their analysis approach was beyond the study scope.

Human factors experts were recruited as they are often employed on a consultancy basis to provide input into accident investigations or safety-critical system design. The views of researchers were also sought to enable a comparison with the practitioners' perspectives and further explore the research-based factors that may influence the SAA research-practice gap.

Participants were required to have experience of investigating accidents and/or performing risk assessments within at least one safety-critical industry. No specific inclusion criteria were set regarding the level of their experience. Participant recruitment was halted when an appropriate level of thematic data saturation was judged to have been achieved.

\subsection{Participants}

Interviews were conducted with 42 participants (age range: 28-79 years; mean age: 46.4 years) based in ten countries. The nine full time accident investigators (Al), 17 health and safety professionals (HS), ten human factors specialists (HFE) and six researchers $(R)$ had experience of working in at least one of 25 industries. Of these industries, those that had been worked in by at least five participants included: rail, aviation, maritime, oil and gas, defence, healthcare, nuclear power and manufacturing. The interviews lasted between 28 and 128 min (mean interview length: $70 \mathrm{~min})$.

\subsection{Interview question design}

The interview questions were designed to understand the following topics: (1) the participants' knowledge of SAA and accident causation, (2) the analysis methods and processes they currently use and (3) the barriers they feel prevent information flowing between the research and practice communities. In order to provide a comprehensive deductive analysis framework, the interview questions were based on these topics, the questions employed by Lundberg et al. (2010) and the findings of previous studies (e.g. Underwood and Waterson, 2012) (see Appendix A for interview questions).

In addition to the interview questions, participants were asked to complete an analysis model awareness table (see Appendix B) which was specifically designed to 
assess their level of awareness and usage of well-known systemic and non-systemic techniques. The STAMP, FRAM and Accimap methods were included as they have been identified as the most frequently cited systemic analysis tools (Underwood and Waterson, 2012). The Swiss Cheese model (Reason, 1997) and Fault Tree Analysis (Watson, 1961) were also included as they are examples of traditional techniques commonly mentioned in the scientific literature (e.g. Katsakiori et al., 2009; Qureshi, 2007; Sklet, 2004).

\subsection{Data collection and analysis}

Five pilot interviews were conducted and analysed. The inter-view schedule was reviewed and amended, where necessary, after each interview. The main interview study was subsequently performed with a minor iteration of the interview schedule generated halfway through the process (wording of two questions was changed). Upon the conclusion of the data collection phase a theoretic (i.e. deductive) and inductive thematic analysis, as described by Braun and Clarke (2006), was performed on the interview transcriptions using NVivo 9.

\subsection{Research-practice gap evaluation framework}

Research-practice gaps signify the impairment of transferring new information between the research and practice communities. The transference process itself, sometimes termed the 'diffusion of innovation', has been the focus of a number of studies which have produced a range of theories and models (e.g. Greenhalgh et al., 2004; Rogers, 2003). Rohrbach et al. (1993) summarised the stages involved in achieving long-term commitment to new ideas which arguably relate to transferring SAA from research into practice. Firstly, the awareness of an innovation, e.g. SAA, is created within the practitioner community. The second and third steps involve practitioners committing to adopt and subsequently implementing the new systemic techniques. These steps were used as a frame-work to evaluate whether issues discovered in the data could affect a given stage and therefore contribute to the formation of a gap.

\section{Findings}

\subsection{Key themes}

The themes which were considered to be key issues, i.e. topics that were mentioned by at least $20 \%$ of the participants, are presented in Table 1. 


\begin{tabular}{|l|c|c|c|c|c|}
\hline \multirow{2}{*}{ Theme (relevant article section) } & \multicolumn{5}{|c|}{ Percentage of participants } \\
\cline { 2 - 6 } & $\begin{array}{c}\text { Accident } \\
\text { investigator }\end{array}$ & $\begin{array}{c}\text { Health and } \\
\text { safety } \\
\text { professional }\end{array}$ & $\begin{array}{c}\text { Human } \\
\text { factors } \\
\text { expert }\end{array}$ & Researcher & Total \\
\hline $\begin{array}{l}\text { 1. Requirement for accountability } \\
\text { influences analysis approach } \\
\text { (3.3.3) }\end{array}$ & 56 & 41 & 30 & 67 & 45 \\
\hline $\begin{array}{l}\text { 2. Model not practitioner focused } \\
\text { (3.3.1) }\end{array}$ & 33 & 24 & 80 & 50 & 43 \\
\hline $\begin{array}{l}\text { 3. Empirical validation } \\
\text { requirements (3.3.4) }\end{array}$ & 11 & 35 & 60 & 50 & 38 \\
\hline $\begin{array}{l}\text { 4. Analyst chooses a technique } \\
\text { that suits the situation (3.4.1 and } \\
\text { 3.6.1) }\end{array}$ & 56 & 35 & 30 & 17 & 36 \\
\hline $\begin{array}{l}\text { 5. Previous experience and training } \\
\text { affects analysis (3.4.2) }\end{array}$ & 67 & 18 & 30 & 50 & 36 \\
\hline $\begin{array}{l}\text { 6. Model suits user's way of } \\
\text { thinking (3.3.2) }\end{array}$ & 22 & 24 & 30 & 67 & 31 \\
\hline $\begin{array}{l}\text { 7. Research considered too } \\
\text { conceptual (3.2.5) }\end{array}$ & 56 & 12 & 30 & 17 & 26 \\
\hline $\begin{array}{l}\text { 8. Analysis time requirements } \\
\text { (3.4.1) }\end{array}$ & 44 & 6 & 40 & 33 & 26 \\
\hline $\begin{array}{l}\text { 9. Company policy affects analysis } \\
\text { (3.5.1) }\end{array}$ & 22 & 18 & 50 & 17 & 26 \\
\hline 10. Amount of training given (3.2.3) & 33 & 24 & 30 & 0 & 24 \\
\hline $\begin{array}{l}\text { 11. User's previous training and } \\
\text { experience affects model } \\
\text { preference (3.3.2) }\end{array}$ & 11 & 24 & 20 & 50 & 24 \\
\hline $\begin{array}{l}\text { 12. Lack of communication } \\
\text { between researcher and } \\
\text { practitioner communities (3.2.5) }\end{array}$ & 56 & 18 & 10 & 0 & 21 \\
\hline
\end{tabular}

Table 1 - Key themes

Whilst the number of participant comments indicates the importance of a given theme, the non-representative nature of the sample means that this cannot be meaningfully tested (see Section 5 for more information). Therefore, the key themes listed in Table 1 are described alongside others that were deemed to influence SAA awareness, adoption and usage and contribute to the research-practice gap.

\subsection{SAA awareness}

\subsubsection{Current level of SAA awareness}

The scientific literature presented in Section 1 describes a general lack of systemic analysis model usage with industry. This situation does not necessarily stem from low levels of SAA aware-ness and comments from several senior practitioners indicate that awareness is growing within industry: 
"Lots and lots of people talk about this [systemic analysis approach] and it's very current in a lot of the safety and high-hazard industry community." (Health and safety professional)

Furthermore, notable remarks from two participants provide evidence that systemic models are currently employed in certain industry sectors. One individual commented that both Accimap and FRAM are used within their national transport accident investigation agency. A second participant with a background in human factors described the Accimap training provided by their organisation to accident investigators within the rail industry.

However, the analysis model awareness table responses obtained from the participants suggest that the majority of practitioners remain unaware of the most frequently cited systemic analysis models, i.e. STAMP, FRAM and Accimap (see Fig. 1) (Underwood and Waterson, 2012).

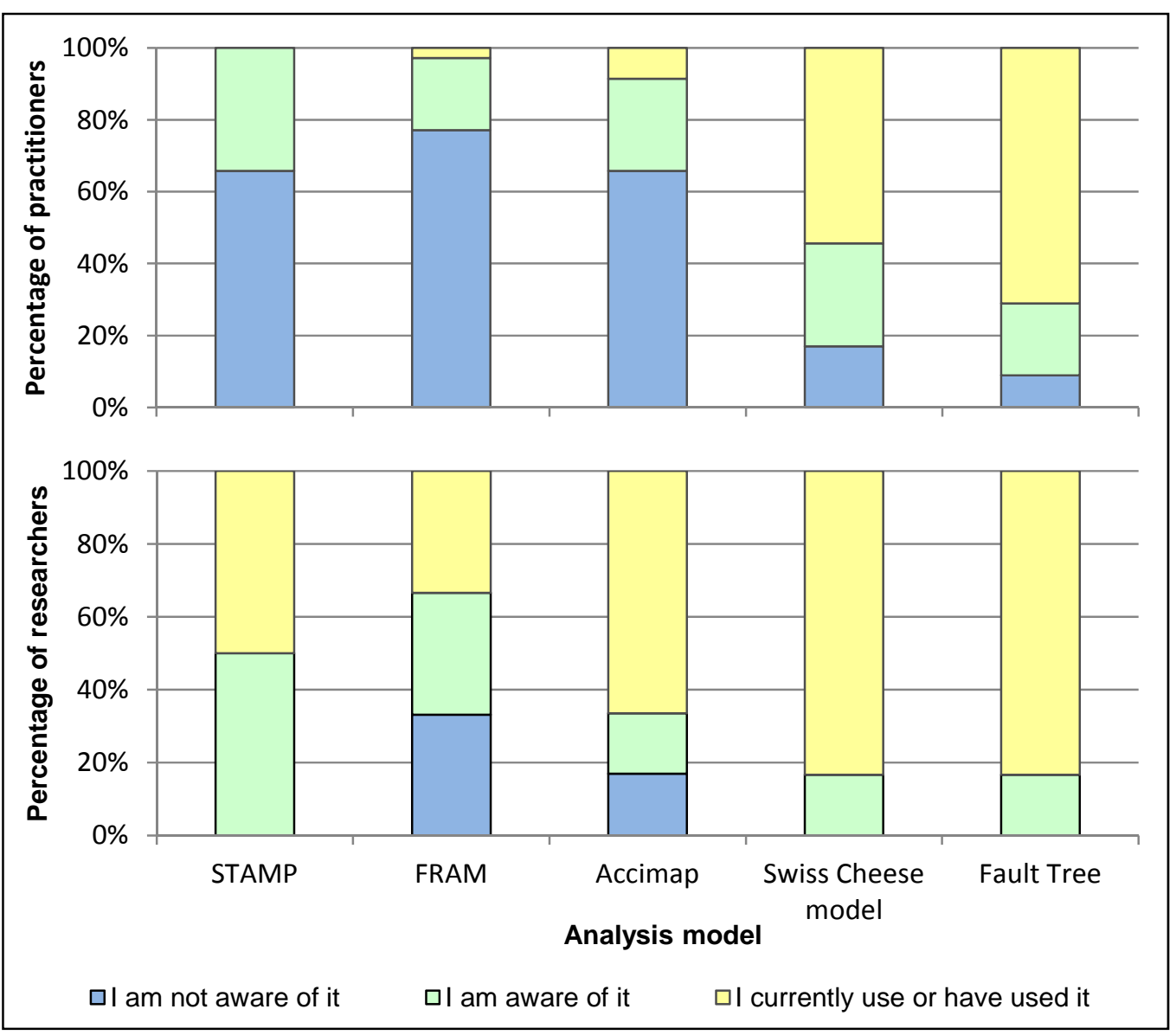

Figure 1 - Analysis model awareness 
This is in contrast to the responses of the researchers who were interviewed and indicates that knowledge and use of these models is greater within the scientific community. The research-based participants only accounted for $14 \%$ of the sample and therefore this comparison must be made tentatively. However, it is indicative of the lack of SAA model usage within industry portrayed in the scientific literature and provides further evidence that a research-practice gap exists.

In addition, a different understanding of SAA seems to exist between the two communities. When asked to provide a description of the 'systems approach to accident analysis', the two most common characteristics mentioned by participants referred to 'component interactions' and 'analysing the whole system', which are key elements of SAA. However, relatively fewer practitioners (AI $=22 \%, \mathrm{HS}=27 \%, \mathrm{HFE}$ $=30 \%$ ) referred to 'component interactions' compared with the researchers $(67 \%)$. The 'analysing the whole system' feature was also referred to by relatively fewer practitioners $(\mathrm{Al}=22 \%, \mathrm{HS}=20 \%, \mathrm{HFE}=40 \%)$ compared with the researchers (50\%). Five practitioners described SAA as a 'systematic' approach, rather than providing examples of 'systemic' analysis characteristics, which suggests a degree of confusion may exist regarding SAA terminology. Furthermore, five practitioners were unable to provide a definition.

\subsubsection{The demand for SAA information}

Whilst there is a clear theoretical argument for the use of SAA (see Section 1), various factors exist which may negate the need or opportunity for a practitioner to seek out a systemic analysis tool. Some practitioners simply have no desire to change their current approach and therefore have no need for new information:

"I can't say that I've actively gone and looked at the new techniques that are out there as the ones l've always used have worked." (Health and safety professional)

Additionally, day-to-day workload demands were considered by some individuals to restrict their learning opportunities:

"I don't have nearly enough time to keep up with the [research] paperwork in this area; hardly any at all. That's a problem that most practitioners have; they're so busy doing investigations it's very difficult to keep up with the theoretical side." (Accident investigator) 
These comments highlight factors which inhibit the search for SAA-related information. However, should a practitioner decide to use a systemic analysis technique, they are still faced with obstacles associated with accessing and utilising the relevant research.

\subsubsection{Extent of training impacts awareness}

An individual's awareness of analysis methods is dictated, at least in part, by the level of training they receive. The extent of training received has clear implications with regards to the opportunity to increase awareness of SAA and comments from participants indicate that levels of training are role-dependent. Full-time investigators, for example, sometimes receive extensive training via university-level courses:

"After you join, the first two years is spent doing a diploma, through a university here, in accident investigation." (Accident investigator)

However, it may also be the case that other practitioners with varying degrees of involvement with accident investigation receive less training:

"We had analytical investigation methods training which was a week-long course. The course started as a week but latterly I think it went down to one and a half days." (Human factors expert)

Several participants with experience in the rail and nuclear sectors remarked that individuals with lower levels of responsibility for accident investigation may not have received any relevant training.

\subsubsection{Accessibility of SAA information}

Individuals who are not provided with SAA training can find gaining access to the relevant information problematic, which may limit their awareness. The time and costs associated with the acquiring the necessary training, for example, may be excessive:

"A lot of time, when you hear about courses, it costs a lot of money to go which dissuaded me from going." (Health and safety professional)

Furthermore, an accident investigator, a health and safety professional and a human factors expert all remarked that the cost of purchasing scientific journal articles and attending conferences may prohibit access to SAA information. 
As well as cost, intellectual property rights can form another barrier to acquiring scientific research information:

"The academic community is very competitive. There's intellectual property rights problems in industry too but normally if there's a buck in it, or a common benefit, you'll collaborate and create an alliance. I find it very hard to get an alliance of academics." (Health and safety professional)

\subsubsection{Communication of SAA information}

Each participant was asked to list the sources of information they utilise in order to keep their knowledge up-to-date. 40 participants provided answers, which are summarised in Table 2.

\begin{tabular}{|l|c|c|c|c|c|}
\hline & \multicolumn{5}{|c|}{ Percentage of participants } \\
\cline { 2 - 6 } Source of information & $\begin{array}{c}\text { Accident } \\
\text { investigator } \\
(\mathrm{n}=9)\end{array}$ & $\begin{array}{c}\text { Health and } \\
\text { safety } \\
\text { professional } \\
(\mathrm{n}=16)\end{array}$ & $\begin{array}{c}\text { Human } \\
\text { factors } \\
\text { expert } \\
(\mathrm{n}=10)\end{array}$ & $\begin{array}{c}\text { Practitioner } \\
\text { total }\end{array}$ & $\begin{array}{c}\text { Researcher } \\
(\mathrm{n}=5)\end{array}$ \\
\hline $\begin{array}{l}\text { Colleagues and } \\
\text { network contacts }\end{array}$ & 56 & 44 & 60 & 51 & 60 \\
\hline Conferences & 33 & 50 & 40 & 43 & 20 \\
\hline Internet searches & 22 & 13 & 10 & 14 & 0 \\
\hline Investigation reports & 11 & 19 & 0 & 11 & 0 \\
\hline $\begin{array}{l}\text { Online forums and } \\
\text { networks }\end{array}$ & 11 & 19 & 0 & 11 & 0 \\
\hline $\begin{array}{l}\text { Practitioner literature } \\
\text { and professional } \\
\text { institutes }\end{array}$ & 33 & 44 & 70 & 49 & 20 \\
\hline Research literature & 22 & 6 & 50 & 23 & 100 \\
\hline Research projects & 0 & 19 & 10 & 11 & 60 \\
\hline Textbooks & 22 & 6 & 10 & 11 & 0 \\
\hline $\begin{array}{l}\text { Training and } \\
\text { experience }\end{array}$ & 44 & 31 & 20 & 31 & 20 \\
\hline $\begin{array}{l}\text { Does not search for } \\
\text { information }\end{array}$ & 0 & 6 & 0 & 3 & 0 \\
\hline
\end{tabular}

Table 2 - Sources of information

Table 2 indicates that the three most popular sources of new information for practitioners, in general, are speaking with colleagues and members of their extended networks, attending conferences and consulting industry literature and professional institutes. In comparison, Table 2 suggests that the majority of researchers tend to gain new knowledge via the scientific literature and by 
conducting research projects, as well as consulting colleagues. The data in Table 2 also suggests that most practitioners do not consult the scientific literature.

Moreover, some of the practitioners specifically remarked on a general lack of communication between the research and practice communities:

"I'm not aware of any real liaison between the two [communities]." (Human factors expert)

"We hardly ever meet people on the theoretical side; it's once in a blue moon." (Accident investigator)

When practitioners do engage with the research community the information presented is considered by some practitioners to be too conceptual and provides little or no practical benefit:

"I know some accident investigators that have been to international conferences where there were lots of academics putting forward papers on approaches to accident investigation. The practitioners in the audience said this is actually meaningless and we don't use it."' (Accident investigator)

Consequently practitioners can develop a sense of disregard for researchers which could further influence the apparent lack of SAA communication:

"There is a mentality within practitioners where academics are seen as people sitting in an ivory tower and haven't had any real expe-rience of accident investigation so [practitioners think] 'how can they comment on investigations?" (Accident investigator)

\subsection{SAA adoption}

\subsubsection{Practicality of analysis method}

Even if sufficient awareness of research is obtained, barriers to its adoption may arise from a lack of consideration for practitioner requirements. The features of an analysis method desired most by participants referred to aspects of usability, such as the simplicity of using a method (see Fig. 2). 


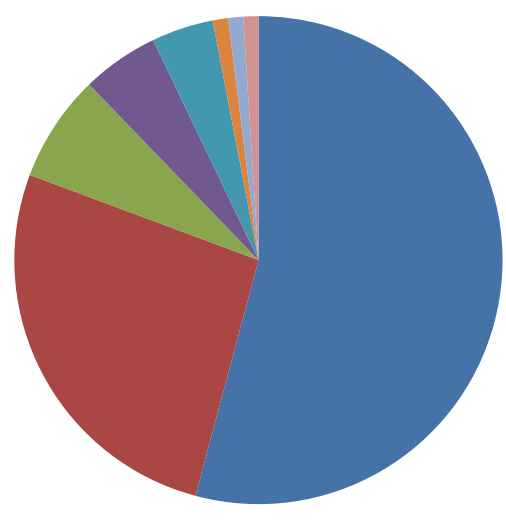

- Usability of method

- Validity of method

- Useful output format

- Software based method

- Reliability of method

- Dynamic modelling capability

- Generic analysis approach

Existing worked examples

Figure 2 - Preferred features of an analysis method

The importance of designing a usable technique was reflected in the comments of several individuals:

"I think if you make it simple, people will use it. If it's complicated, they won't and it becomes another job that's too difficult to do and it gets put on the shelf." (Health and safety professional)

Other practicality-related issues which may inhibit the adoption of research were also referred to by participants. Several accident investigators, for example, commented on a possible lack of appreciation for the practicalities of their role in the design of analysis methods. The potentially excessive cost of implementing research was also highlighted by a human factors expert.

\subsubsection{Personal adoption criteria}

In addition to the practicalities of using an analysis technique, adoption may also be influenced by a number of factors based on an individual's personal preference and experience. A person's decision to adopt a method may be, for example, based on how well it suits their way of thinking:

"When I think of the Swiss Cheese model, I can really think of those barriers being broken and trying to find out why they have been broken. For me it's a very natural way of investigating. Some people really hate it but for me it works." (Accident investigator)

The preference for a given model can also be influenced by an individual's previous experience and training: 
"If I had trained with other people I would probably have a very different default model that I use. I think it's mostly my [educational] upbringing that makes it very difficult to think of anything else." (Researcher)

Experience gained by analysis method usage was specifically highlighted by several participants who remarked that their decision to adopt a technique was based upon the outcome of an initial trial period.

\subsubsection{Accountability influences analysis approach}

The analysis approach taken by a practitioner can be influenced by their need to assign liability for an accident. Some individuals remarked that they prefer or are mandated to avoid seeking blame in favour of focusing on safety improvements, as per the systems approach. However, other practitioners who are more concerned with the commercial and legal implications of accidents may seek to apportion blame:

"The way the analysis was set up was really to assist with legal proceedings. That was the main driver. . . [it was] not always to find out what the root cause was. It would be more to do with whether a prosecution was likely to be successful or not." (Human factors expert)

This is particularly evident when those who are conducting an investigation may be deemed culpable and are incentivised to apportion liability elsewhere:

"Because it's the manager that carries out the industry's own investigation they're not really going to look at themselves and they're certainly not going to look at their own management chain because that puts them in a threatening position." (Accident investigator)

In addition to the influence on SAA adoption, the need to demonstrate liability can also influence the use of an analysis technique. One health and safety professional, for example, referred to the occasions where he was instructed by clients to use their analysis tools in particular ways in order to avoid 'black spots' on their safety records.

\subsubsection{Model validation}

The extent of an analysis model's empirical validation was considered by many practitioners to be a key influence on their adoption decision. Several participants commented on the need for extensive validation to demonstrate that a method has been 'proven' and can be 'trusted': 
"Has it been tried and tested? Does it add value? We have to ask these questions when we implement something." (Health and safety professional)

A number of individuals who provide consultancy services in accident investigation and risk analysis specifically commented on the importance of a method's track record when attempting to establish the credibility of their work with clients. However, less consideration was given to the extent of a method's conceptual validity:

"Validity comes very much down the line. I think it's very much about quickness and whether the technique is understood in the community, if I'm brutally honest." (Health and safety professional)

\subsection{SAA usage}

\subsubsection{Usage resource constraints}

The level of effort invested in an analysis will be based, at least in part, by the resources available to the investigation team:

"There's a 14 out of 15 chance that we're not going to go to an investigation that we should do and that's simply because of funding." (Accident investigator)

Consequently this can affect whether an individual employs more complex analysis techniques, such as those based on the systems approach:

"[Name of method] is something that l've been trained in but l'd only use it if there had been a major incident, whereas the 5 Whys method (Ohno, 1988) is probably a starting point for a nice and simple easy one. I think the more complex the incident you'd pull in more of the techniques to give you the answer." (Health and safety professional)

In addition to whether an analysis method is used, the time and financial constraints involved in accident investigation can also affect how it is used. Several participants, for example, remarked that the depth of analysis they can achieve with their preferred technique is limited by the time available to them.

\subsubsection{Model reliability}

If a systemic analysis technique is adopted by a practitioner there are factors related to reliability which will affect its usage. A number of participants remarked on the influence that an individual's background and experience has on their analysis 
approach and how this can produce variation in investigation findings. Open discussions and analysis reviews which result in a consensus on the investigation findings can help minimise the biasing effects of individuals' backgrounds; a process which is common with full-time investigators:

"The inspector will do a very structured presentation to a group of inspectors where we challenge what he's done, what he's said and what evidence he's got that's sufficient to make the conclusions that he's drawing together." (Accident investigator) However, several participants commented on how the qualitative nature of the systemic analysis tools could increase the difficulty of reaching such an agreement:

"If you turned up with an Accimap and said 'the system is safe because I've analysed it in an Accimap' you'd just get laughed out of the room. They'd pick it to pieces because it's far more subjective." (Human factors expert)

\subsubsection{Data requirements of SAA}

Several factors relating to the data requirements of SAA were considered by participants to impact on their ability to use the systemic analysis methods. For example, the system-wide data needed to perform SAA is not always available:

"If I were to go and work in industry now I think I would have to revert back to more simple accident analysis methods just because the data wouldn't be there to support them [the SAA methods]." (Researcher)

Some practitioners mentioned that the accident information databases they are required to use employ coding taxonomies which reflect the theoretical (cause-effect) underpinnings of sequential techniques. This may influence the type of data that is collected and one individual observed that, even if they gather data relevant to SAA, they must transpose their findings into a non-systemic format.

These issues appear to stem, in part, from the fact that researchers and practitioners have fundamentally different approaches to analysis and therefore different data requirements:

"Sometimes I do feel there is an important division between how practitioners and some academics treat accident investigation. We're always looking at specifics and therefore evidence will some-times take us down a very specific path and we don't 
need to consider the wider aspects and vulnerabilities of the system." (Accident investigator)

\subsection{Organisational influences on the research-practice gap}

\subsubsection{Organisational policy}

Some individuals have the freedom to choose which analysis technique they adopt and use. However, in many cases, organisational policy dictates which methods are used:

"We tend to find that when people come here [for investigation training] they want to know all about the models and how to use all of them but often they go back to an organisation that says 'this is what we use' so they don't really get the opportunity." (Researcher)

Practitioners who provide investigation services on a consultancy basis also commented that requests from some clients to use in-house analysis techniques can produce similar barriers to analysis tool usage. Organisational policy can also impact on the resources available for practitioners to learn and use new analysis methods and therefore create the issues described in Sections 3.2.3 and 3.4.1.

A link between safety culture and organisational policy was referred to by several individuals who observed that their analysis approaches were, in part, dictated by the senior management and the safety culture they instilled. A number of participants also commented that safety-related changes they recommended to senior management teams, such as introducing new accident investigation policies, sometimes needed to be presented in cost-benefit, rather than safety improvement, terms:

“When I turned up at [company name] there was no health and safety. They didn't care about which safety regulation said they had to do risk assessments. What I had to do was sell them the cost-effectiveness [of safety]. When I put it into a dollar sign they understood it and then their attitude became 'this is good for the company and it prevents reputational damage as well."' (Health and safety professional) 


\subsection{Industry influences on the research-practice gap}

\subsubsection{Regulatory requirements}

The degree of regulation within a given industry can have a large influence on what type of analysis techniques are used in accident investigation and risk assessments:

"Regulators [in the nuclear industry] dictate exactly what methods need to be used and they're very slow to update their opinions on these things." (Human factors expert)

"There is a degree of flexibility. No one is telling me that I have to use the Swiss Cheese model and that is it. This is an International Maritime Organisation resolution, don't forget, and is not mandatory." (Accident investigator)

The comments of many practitioners indicated that SAA-based regulation is not in place across industry in general. This may be due to a lack of SAA awareness at the regulatory level, rather than a decision to reject it:

“The regulation probably doesn't recognise [the systems approach] or encourage it at the minute. I don't know about the military or anyone like that but certainly in the railway industry it doesn't seem to." (Health and safety professional)

\subsubsection{Industry characteristics}

In addition to the regulatory environment of an industry, the suitability of performing SAA within a given industry may depend on a range of domain characteristics, e.g. degree of operational complexity:

"If you look at highly dynamic, very complex systems then the systems approach is more appropriate. If you're looking at things like the manufacturing industry, it's probably less appropriate, and things like the Bowtie method or something a bit more linear is probably more suitable." (Human factors expert)

"If you are in a highly defined, highly automated environment requiring software reliability, for instance in medical systems, then it makes absolute sense to use the STAMP technique. It's an issue of horses for courses." (Health and safety professional) 


\subsubsection{Resistance to change}

The effort and cost of implementing an innovation, such as SAA, within an organisation or throughout an industry by means of new regulations can create resistance to change. This inertia can increase with the level of regulation:

"Once you get a nuclear power plant licensed you don't ever want to change it because you've spent so much money. So, by its very nature, a very heavily regulated industry cannot be innovative." (Health and safety professional)

"I would say changing anything in healthcare at a national level is really, really difficult. It takes a long time and there's a lot of consultation involved. If we were going to change the way we work, there's huge numbers of people who have a stake in what we do." (Human factors expert)

\section{Discussion}

The topics presented in Section 3 describe a wide range of issues that can affect if, and how, research is applied by practitioners. When considering all of these factors together they can be viewed as providing a wider context in which the research practice-gap is played out. Whilst not an exhaustive list, it is believed that the range of themes included in Section 3 is comprehensive enough to provide an adequate representation of the gap. The findings are graphically summarised in Fig. 3, which is based on the evaluation framework derived from the work of Rohrbach et al. (1993) (see Section 2.5). 


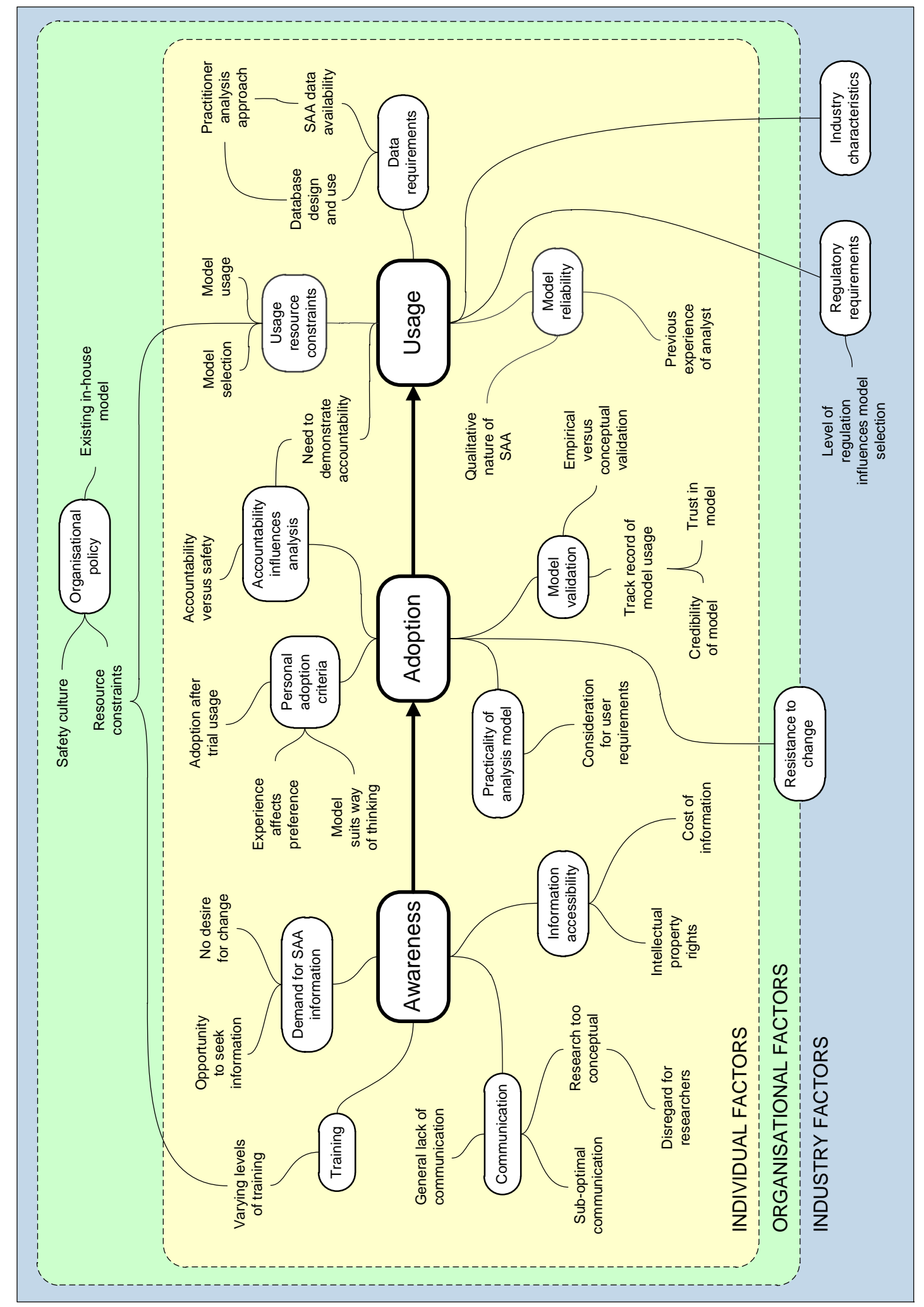

Figure 3 - The SAA research-practice gap

Discussion on the features of the gap and the implications for SAA is provided in the remainder of Section 4. 


\subsection{Issues associated with the research-practice gap}

The majority of issues raised by participants may contribute, at least in part, to a general gap between accident analysis research and practice. Therefore, these factors could hinder the success of any new analysis method, regardless of its theoretical under-pinning. What then are the characteristic features of the SAA research-practice gap? This question is explored further within the context of SAA awareness, adoption and usage in the rest of Section 4.1.

\subsubsection{SAA awareness}

The opportunity to learn about new analysis techniques, e.g. via training (see Section 3.2.3), access to and the communication of the relevant information (see Sections 3.2.4 and 3.2.5) will affect a practitioner's awareness of any technique. However, it is worth commenting on how these issues relate to SAA. It is acknowledged within the literature that SAA requires extensive theoretical and domain knowledge, training and for-mal education (e.g. Hollnagel and Speziali, 2008; Johansson and Lindgren, 2008; Salmon et al., 2012a; Sklet, 2004).

It is therefore conceivable that practitioners will only be made aware of systemic analysis tools in the more in-depth training courses. In addition, it is the belief of the authors that the majority of SAA information is presented via the scientific literature and at conferences. SAA has been presented at conferences (e.g. Kazaras and Kirytopoulos, 2011; Underwood and Waterson, 2012), however, as conferences appear to be the third most popular source of information for practitioners (see Table 2 ), it is arguable that SAA is not being promoted in the most effective way.

The cost of training, scientific literature and conference proceedings can limit SAA awareness. However, information regarding SAA is freely available on the internet from sources such as Google Scholar, Nancy Leveson's MIT website (http://sunnyday.mit.edu/) and Erik Hollnagel's FRAM related website (http://www.functionalresonance.com/). This suggests that it is the issues surrounding SAA communication (see Section 3.2.5) that may be a more significant influence on awareness. Given that practitioners can lose interest in research that is too conceptual it is possible that the considerable amount of accident causation theory present in the systems approach literature may dissuade them from learning more about SAA. 


\subsubsection{SAA adoption}

As with the awareness of SAA, there are several factors related to the adoption of an analysis technique which are influenced by features of the systems approach.

The importance of an analysis method's usability was reflected in the comments of practitioners (see Section 3.3.1). Whilst there is varying opinion within the literature with regard to the usability of the systemic analysis techniques their use has been viewed in some cases as time-consuming (e.g. Ferjencik, 2011; Johansson and Lindgren, 2008; Salmon et al., 2011). This issue can become increasingly problematic for individuals whose main responsibilities do not include the investigation of accidents, as they may have less time to conduct analyses. SAA may not be suited to and, therefore, adopted by them.

The notion that more effective safety recommendations can be devised by the avoidance of blaming a suitable culprit is well established in the SAA literature (e.g. Leveson, 2004) and was echoed in the comments of several participants (see Section 3.3.3). How-ever, searching for human error makes it easier to find out who is responsible for an accident and various practitioners emphasised that demonstrating accountability, particularly from a legal or commercial perspective, is still an objective of accident investigation (Reiman and Rollenhagen, 2011). Therefore, practitioners may be incentivised to use non-systemic analysis techniques to ease the identification of culpable personnel (Underwood and Waterson, 2012).

Most practitioners in safety-oriented businesses tend to prefer well established methods; a point which was raised by the participants (Johansson and Lindgren, 2008). Although STAMP, FRAM and Accimap have been applied across a variety of safety-critical domains this has mainly taken place within an academic context, e.g. accident analysis case studies (e.g. Salmon et al., 2012a). The comments of participants, therefore, suggest that SAA methods will require considerable empirical validation within an industrial set-ting if they are to gain acceptance from practitioners (see Section 3.3.4).

\subsubsection{SAA usage}

If a practitioner takes the decision to adopt a systemic analysis method they are faced with several issues which can hinder the application of SAA. 
SAA is not a simple endeavour and requires significant analyst effort and access to various subject matter experts (Salmon et al., 2012b). SAA may, therefore, only be suited to major accident investigations where funding, time and personnel are sufficient to obtain the amount of information required for SAA. Indeed, both Leveson (2004) and Salmon et al. (2012b) suggest that the data requirements of STAMP and Accimap are only typically met via the comprehensive reports produced after a large scale accident.

Furthermore, individuals may not be able to gain access to the data required for SAA. For example, such information may exist outside of the organisation 'affected' by the accident (e.g. commercially sensitive documentation from an equipment supplier) or an individual may be in the 'wrong' position within an organisation to address the whole scope of an accident (e.g. unable to interview senior managers) (Dien et al., 2012). In addition to the varying levels of information access, the type of data that is collected can also influence the application of SAA. Accident data is reported, collected and compiled in databases over time in line with national regulations and established codification systems (Mullai, 2004; Mullai and Paulsson, 2011). However, in some cases these databases and coding schemes are not based around the systems approach (e.g. they just focus on local events at the 'sharp end' of a system) and the information required to populate them is, there-fore, unlikely to enable thorough SAA (Roelen et al., 2011; Salmon et al., 2012b).

\subsubsection{Organisational and industry issues}

A significant influence on a practitioner's selection of a model is the safety culture of their organisation. The comments of a number of participants (see Section 3.5.1) reflect the findings of Lundberg et al. (2012), who suggest that four aspects of safety culture can influence the decision to implement safety-related changes: institutionalised low safety standards, prioritisation of safety, the decision making criteria to adopt changes and the level of resources allocated to implement them. These factors clearly apply to the implementation of any new analysis method. However it is arguable that, in some cases, obtaining organisational (or regulatory) commitment to making a fundamental shift to employ SAA may be harder than implementing a modification of an existing sequential technique. 
The comments from practitioners (see Section 3.6.2) indicate that, depending on the industry in question, the use of SAA may not always be appropriate. This notion is supported by Hollnagel and Speziali (2008) who suggest that systemic models are best suited to accidents within highly complex, intractable systems, e.g. nuclear power plants. Therefore, whilst the generic nature of the systemic models means that they can be applied in any domain, the notion that 'one size does not fit all' means that the resulting 'competition' from other analysis techniques represents a further barrier to SAA adoption (Mullai and Paulsson, 2011; Salmon et al., 2012a).

However, although new models often criticise or even disqualify older ones, in reality these different techniques can complement each other due to their own strengths and weaknesses (Jacobsson et al., 2009). This issue has been examined in studies which combined systemic and non-systemic techniques (e.g. Ferjencik, 2011; Kontogiannis and Malakis, 2012) and suggest that a more insightful analysis is achieved compared to that when using a single model. This indicates that aspects of SAA may be successfully utilised in many industries, regardless of their complexity.

\subsection{Does the SAA research-practice gap need to be closed?}

So far, this article has described and discussed a number of features that may prevent the use of SAA techniques by practitioners. An important question that naturally follows this discourse is 'does the SAA research-practice gap need to be closed?'

The proposed benefits of SAA presented in Section 1, i.e. gaining an improved understanding of accidents which may lead to more effective recommendations, suggest that it should be. Research that has compared SAA methods with nonsystemic analysis techniques indicates that these benefits can be achieved and, therefore, that SAA should be promoted throughout safety critical domains (see Section 1.1). Whilst sequential techniques may remain effective in certain circumstances, e.g. the analysis of less complex systems or of subsystems/components, the ever-rising complexity of socio-technical systems suggests that the use of SAA will become increasingly important in the future (Hollnagel and Speziali, 2008; Salmon et al., 2011).

However, the difference between SAA and the current practices of some accident investigators seems to be a subtle one. The Swiss Cheese model (SCM), which has 
been widely adopted in various industries (e.g. healthcare and aviation) is described as a sequential technique by some researchers (e.g. Hollnagel, 2012; Leveson, 2011). However, it does provide a holistic multi-level analysis approach, as per SAA, and later versions of the model (see Reason, 1997) also take account of the fact that 'active failures' are not required for an accident to occur. Additionally, a number of organisations have purposely neutralised the language used in their SCM-based models to avoid attributing blame, such as the Australian Transport Safety Bureau and EUROCONTROL. Even within the research community, confusion exists over whether the SCM is a systemic technique, as exemplified by researchers who cite it (and methods based on it) as such (e.g. Salmon et al., 2012a; Stanton et al., 2012). Therefore, acknowledging the existence of a SAA research-practice gap seems to depend on which view of accident causation is taken by an individual.

Despite this ambiguity, what seems clear is that SAA methods are theoretically capable of providing useful insights into complex socio-technical system accidents which are not generated by many traditional analysis techniques. Therefore, efforts to increase practitioner awareness, adoption and usage of SAA should be made.

\subsection{Bridging the SAA research-practice gap}

Whilst one of the factors presented in Section 3 may be sufficient to prevent a practitioner from conducting SAA, it is more likely that they all, to a greater or lesser extent, combine to inhibit the application of the systems approach. So, if the SAA research-practice gap is to be closed, which of issues presented in Section 3 should be tackled? An initial step in answering this question can be made by considering the key themes contained in Table 1. The majority of these themes focus on two aspects: ensuring that the SAA methods meet the needs of the practitioners (themes 2-4, 8); communicating SAA research in a more effective manner (themes 5, 7, 9-12).

In order to meet the analysis needs of practitioners, it must be established if, and how, the systemic methods need to be adapted to meet the demands of live investigations and accident trend analysis. This process has begun and discussions between the two communities are taking place, e.g. the annual STAMP and FRAM workshops organised respectively by Nancy Leveson and Erik Hollnagel. However, to the authors' knowledge, practitioner feedback has yet to be widely publicised. Therefore, further efforts should be made to establish whether the SAA methods can 
be effectively applied in industry. Ideally, this work would involve recruiting accident investigators to use, evaluate and help refine the systemic techniques; a process that was also involved in successfully establishing other analysis methods, such as HFACS (Shappell and Wiegmann, 2000) and Tripod Delta (Hudson et al., 1994). As indicated by the data presented in Fig. 2, the evaluations should initially focus on the methods' usability, validity and the usefulness of their outputs. This process would bring the added advantage of providing a degree of empirical validation and help create the 'track record' desired by various elements of the practitioner community. Given that there may be reluctance to trial a new technique in live investigations, the use of high-fidelity simulated investigations would provide a suitable alternative. Research should also be conducted into developing industry-specific taxonomies for classifying contributing systemic factors to improve the reliability of the SAA methods and their suitability for multiple accident case analysis (Salmon et al., 2012a).

Achieving more effective communication of SAA research to practitioners can be accomplished via a number of routes. Table 2 suggests that, along with continued presentation of research at conferences, promoting SAA within the practitioner literature and professional institutes would increase the awareness of many practitioners. Steele and Pariès (2006) comment that successful communication of 'less traditional' perspectives on accident causality to practitioners target the layperson, convincingly summarise such ideas and make them seem like common sense. Information created for the practitioner-focused literature should be produced to meet these criteria. This may be particularly relevant for practitioners who only have a part-time involvement in accident investigation. Increasing the amount of SAA information provided in accident analysis training offers another important option for increasing awareness and adoption of systemic methods. Ideally this training would be conducted strategically to maximise its impact. As a starting point, the training should be provided to accident investigation trainers. This would utilise an existing net-work of professional trainers that can act as effective and efficient interface between the researcher and practitioner communities. Ideally, industry regulators and senior safety managers should also be trained in SAA. If the regulators and organisations formally adopt SAA then the need/requirement for individuals to employ systemic techniques in accident analysis will increase. However, until a SAA track record can be established in industry, it is unlikely that regulators and 
organisations will commit to formally adopt and use the systemic analysis techniques. Therefore, achieving this commitment is likely to be a long-term aim of bridging the research-practice gap.

\subsection{Can the SAA research-practice gap be closed?}

Whilst the proposed solutions described in Section 4.3 offer a means of bridging the research-practice gap, it may not be possible to completely close it. A number of researchers (e.g. Dekker, 2011; Stanton et al., 2012; Zio and Ferrario, 2013) are continuing to explore the nature of systemic accidents by considering the behaviour of ever-larger 'systems of systems'. For example, the drift into failure concept proposed by Dekker (2011) promotes looking 'up and out' at various factors which operate at a global level, such as sociological and political conditions, and how they affect system safety. Investigating and rectifying such issues is likely to remain beyond the scope of accident investigation, at least in the short term, due to a variety of issues such as resource constraints. There-fore, whilst is it is the role of the research community to further the understanding of systemic accidents, some of this knowledge may not be practicable to apply. However, efforts should still be made to bridge the research-practice gap so that SAA knowledge can be utilised when possible.

\section{Study limitations}

Given that this study utilised a non-representative convenience sample, as indicated in Section 3.1, a number of limitations were placed on the findings. For example, statistically testing the relative importance of themes identified by the participants or the differences observed across roles, industries and countries would not produce results that could be generalised. This means that the representation of the research-practice gap in Fig. 3 can only present the contributing factors, rather than their relative influence. However, the use of a convenience sample resulted from the resource constraints of the study rather than a lack of consideration of sample design. Given the number of people who are involved in accident analysis, achieving a representative sample from which results could be generalised would be a significant challenge. Despite the limitations imposed by the nature of the sample, the authors believe that the findings of this study offer some useful insights and direction for future work. 


\section{Conclusions}

The systems approach is arguably the dominant concept within accident analysis research. Its application, via systemic accident analysis (SAA), supposedly provides an improved description of accident causation, avoids the incorrect apportioning of blame for an accident and helps inform more effective safety recommendations. However, despite the suggested benefits of SAA, evidence within the scientific literature indicates that systemic analysis models and methods are not being widely used in practice. This implies that a research-practice gap exists which impacts on the awareness, adoption and usage of SAA.

This study examined various issues stemming from both the research and practice communities which may hinder the application of SAA. Some of these factors are indicative of a general research-practice gap in accident analysis. However, others are more pertinent to SAA, such as its lack of track record within industry and the possible incentive to use non-systemic techniques to facilitate the attribution of liability. The benefits of SAA suggest that the research-practice gap should be closed. Efforts to bridge the gap should focus on ensuring that SAA methods meet the needs of practitioners and improving the communication of SAA research.

\section{Appendix A}

\section{Interview questions}

\section{Background information}

1. What is your age?

2. What is your current job title?

3. What are the main duties of your current role?

4. As a percentage, how much of your time is spent analysing accidents?

5. How many years of experience do you have of analysing accidents?

6. How many accidents have you analysed?

7. What types of accidents have you analysed?

8. Which industries did these accidents occur in?

9. When would you be called into perform an analysis/risk assessment?

10. In your opinion, what is the main reason why major accidents within the industry you work in?

$$
\text { 10.1 Why? }
$$


The systems approach

11. Have you heard of the systems approach?

12. What is your understanding of the systems approach to accident analysis?

12.1 How did you gain this understanding?

13. Do you apply a systems approach to accident analysis?

13.1 How do you apply it?

14. What do you think the benefits of using the systems approach are?

15. What are the drawbacks of using the systems approach?

The current approach

16. When you perform an analysis, what steps do you go through?

17. How much time is spent on analysing the data compared with its collection and report writing?

18. What method(s) do you currently use to analyse accidents?

19. What made you choose that specific method?

20. What are the benefits of the method?

21. What are the drawbacks of the method? 22.

What other methods did you consider?

23. Why is your current method better than the alternatives?

24. When selecting a method what consideration do you give to:

24.1 Validity and reliability?

24.2 Usability?

24.3 How it helps you generate recommendations?

25. If I asked you to write a wish list of the features that your ideal analysis technique would possess, what would you write?

Research-practice gap

26. How do you keep up-to-date with new analysis theories and methods?

27. What sort of input would you value from the researcher/practitioner community?

28. What are the barriers which prevent the application of accident analysis research?

29. How do you think those barriers could be removed? 


\section{Appendix B}

\begin{tabular}{|c|c|c|c|c|c|}
\hline $\begin{array}{c}\text { Analysis } \\
\text { tool }\end{array}$ & $\begin{array}{c}\text { I have } \\
\text { never } \\
\text { heard of } \\
\text { it }\end{array}$ & $\begin{array}{c}\text { I have } \\
\text { heard of it } \\
\text { but don't I } \\
\text { know how } \\
\text { it works }\end{array}$ & $\begin{array}{c}\text { I understand } \\
\text { how it works } \\
\text { but I have } \\
\text { never used } \\
\text { it }\end{array}$ & $\begin{array}{c}\text { I have used } \\
\text { it before but } \\
\text { do not use it } \\
\text { currently }\end{array}$ & $\begin{array}{c}\text { I } \\
\text { currently } \\
\text { use it }\end{array}$ \\
\hline STAMP & & & & & \\
\hline FRAM & & & & & \\
\hline Accimap & & & & & \\
\hline $\begin{array}{c}\text { Swiss } \\
\text { Cheese }\end{array}$ & & & & & \\
\hline MORT & & & & & \\
\hline $\begin{array}{c}\text { Fault } \\
\text { Tree } \\
\text { Analysis }\end{array}$ & & & & & \\
\hline $\begin{array}{c}\text { Domino } \\
\text { model }\end{array}$ & & & & & \\
\hline
\end{tabular}

STAMP: Systems-Theoretic Accident Model and Processes

FRAM: Functional Resonance Accident Model

MORT: Management Oversight and Risk Tree

\section{References}

Belmonte, F., Schoen, W., Heurley, L., Capel, R., 2011. Interdisciplinary safety analysis of complex socio-technological systems based on the functional resonance accident model: an application to railway traffic supervision. Reliability Engineering \& System Safety 96 (2), 237-249.

Braun, V., Clarke, V., 2006. Using thematic analysis in psychology. Qualitative Research in Psychology 3 (2), 77-101.

Carhart, N., Yearworth, M., 2010. The use of system dynamics group model building for analysing event causality within the nuclear industry. In: Moon, T. (Ed.), 28th International Conference of the System Dynamics Society. 25-29 July 2010, The System Dynamics Society.

de Carvalho, P.V.R., 2011. The use of functional resonance analysis method (FRAM) in a mid-air collision to understand some characteristics of the air traffic management system resilience. Reliability Engineering \& System Safety 96 (11), 1482-1498. 
Dekker, S., 2011. Drift into Failure: From Hunting Broken Components to understanding Complex Systems. Ashgate Publishing Company, Farnham.

Dien, Y., Dechy, N., Guillaume, E., 2012. Accident investigation: from searching direct causes to finding in-depth causes-problem of analysis or/and of analyst? Safety Science 50 (6), 1398-1407.

Energy Institute, 2008. Guidance on Investigating and Analysing Human and Organisational Factors Aspects of Incidents and Accidents. Energy Institute, London.

Ferjencik, M., 2011. An integrated approach to the analysis of incident causes. Safety Science 49 (6), 886-905.

Greenhalgh, T., Robert, G., Macfarlane, F., Bate, P., Kyriakidou, O., 2004. Diffusion of innovations in service organizations: systematic review and recommendations. Milbank Quarterly 82 (4), 581-629.

Health and Safety Executive, 2004. Investigating Accidents and Incidents: A Workbook for Employers, Unions, Safety Representatives and Safety Professionals, 2nd edn. HSE Books, Sudbury.

Herrera, I.A., Woltjer, R., 2010. Comparing a multi-linear (STEP) and systemic (FRAM) method for accident analysis. Reliability Engineering \& System Safety 95 (12), 1269-1275.

Hollnagel, E., 2012. FRAM-The Functional Resonance Analysis Method. Ashgate, Farnham. Hollnagel, E., 2004. Barriers and Accident Prevention. Ashgate Publishing Limited, Aldershot.

Hollnagel, E., Speziali, J., 2008. Study on developments in accident investigation methods: a survey of the state-of-the-art. SKI Report 2008:50. École des Mines de Paris, Sophia Antipolis, France.

Hudson, P.T.W., Reason, J.T., Wagenaar, W.A., Bentley, P.D., Primrose, M., Visser, J.P., 1994. Tripod delta: proactive approach to enhanced safety. Journal of Petroleum Technology 46 (1), 58-62.

Jacobsson, A., Sales, J., Mushtaq, F., 2009. A sequential method to identify underlying causes from industrial accidents reported to the MARS database. Journal of Loss Prevention in the Process Industries 22 (2), 197-203.

Jenkins, D.P., Salmon, P.M., Stanton, N.A., Walker, G.H., 2010. A systemic approach to accident analysis: a case study of the Stockwell shooting. Ergonomics $53(1), 1-17$.

Johansson, B., Lindgren, M., 2008. A quick and dirty evaluation of resilience enhancing properties in safety critical systems. In: Hollnagel, E., Pieri, F., Rigaud, E. (Eds.), Third Symposium on Resilience Engineering. 28-30 October 2008, École des mines de Paris.

Johnson, C., 2003. Failure in Safety Critical Systems: A Handbook of Incident and Accident Reporting. Glasgow University Press, Glasgow.

Johnson, C.W., de Almeida, I.M., 2008. An investigation into the loss of the Brazilian space programme's launch vehicle VLS-1 V03. Safety Science 46 (1), 38-53.

Katsakiori, P., Sakellaropoulos, G., Manatakis, E., 2009. Towards an evaluation of acci-dent investigation methods in terms of their alignment with accident causation models. Safety Science 47 (7), 1007-1015. 
Kazaras, K., Kirytopoulos, K., 2011. Applying stamp in road tunnels hazard analysis. In: 6th IET International Conference on System Safety, 20-22 September 2011, IET, pp. 1-6.

Kontogiannis, T., Malakis, S., 2012. A systemic analysis of patterns of organizational breakdowns in accidents: a case from helicopter emergency medical service (HEMS) operations. Reliability Engineering \& System Safety 99, 193-208.

Leveson, N., 2011. Engineering a Safer World: Systems Thinking Applied to Safety. The MIT Press, London.

Leveson, N., 2004. A new accident model for engineering safer systems. Safety Science 42 (4), 237-270.

Lindberg, A., Hansson, S.O., Rollenhagen, C., 2010. Learning from accidents-what more do we need to know? Safety Science 48 (6), 714-721.

Lundberg, J., Rollenhagen, C., Hollnagel, E., 2010. What you find is not always what you fix-how other aspects than causes of accidents decide recommendations for remedial actions. Accident Analysis \& Prevention 42 (6), 2132-2139.

Lundberg, J., Rollenhagen, C., Hollnagel, E., Rankine, A., 2012. Strategies for dealing with resistance to recommendations from accident investigations. Accident Analysis and Prevention 45, 455-467.

Martinez, E., 2011. Investigation-a shared process. ISASI Forum: Air Safety through Investigation 44 (4), 7-11.

Mullai, A., 2004. A risk analysis framework for marine transport of packaged dangerous goods. In: Brindley, C. (Ed.), Supply Chain Risk. Ashgate Publishing Ltd., Aldershot, pp. 130-159.

Mullai, A., Paulsson, U., 2011. A grounded theory model for analysis of marine accidents. Accident Analysis \& Prevention 43 (4), 1590-1603.

Ohno, T., 1988. Toyota Production System: Beyond Large-scale Production. Productivity Inc., Portland.

Okstad, E., Jersin, E., Tinmannsvik, R.K., 2012. Accident investigation in the Norwegian petroleum industry-common features and future challenges. Safety Science 50 (6), 1408-1414.

Qureshi, Z.H., 2007. A review of accident modelling approaches for complex sociotechnical systems. In: Cant, T. (Ed.), 12th Australian Workshop on Safety Related Programmable Systems. 2007, Australian Computer Society, pp. 47-59.

Rail Safety Standards Board, 2011. Investigation Guidance Part 3: Practical Support for Accident Investigators. Rail Safety and Standards Board, London.

Rasmussen, J., 1997. Risk management in a dynamic society: a modelling problem. Safety Science 27 (2-3), 183-213.

Reason, J., 1997. Managing the Risks of Organizational Accidents. Ashgate Publishing Ltd., Aldershot.

Reiman, T., Rollenhagen, C., 2011. Human and organizational biases affecting the management of safety. Reliability Engineering and System Safety 96, 1263-1274.

Robson, C., 2002. Real World Research: A Resource for Social Scientists and Practitioner-Researchers, 2nd edn. Blackwell Publishing, Oxford. 
Roelen, A.L.C., Lin, P.H., Hale, A.R., 2011. Accident models and organisational factors in air transport: the need for multi-method models. Safety Science 49 (1), 510.

Rogers, E.M., 2003. Diffusion of Innovations, 5th edn. Free Press, New York.

Rohrbach, L.A., Graham, J.W., Hansen, W.B., 1993. Diffusion of a school-based substance abuse prevention program: predictors of program implementation. Preventive Medicine 22 (2), 237-260.

Salmon, P.M., Cornelissen, M., Trotter, M.J., 2012a. Systems-based accident analysis methods: a comparison of Accimap, HFACS, and STAMP. Safety Science 50 (4), 1158-1170.

Salmon, P.M., McClure, R., Stanton, N.A., 2012b. Road transport in drift? Applying contemporary systems thinking to road safety. Safety Science 50 (9), 1829-1838.

Salmon, P.M., Stanton, N.A., Lenné, M., Jenkins, D.P., Rafferty, L., Walker, G.H., 2011. Human Factors Methods and Accident Analysis: Practical Guidance and Case Study Applications. Ashgate Publishing Ltd., Farnham.

Shappell, S., Wiegmann, D., 2000. The Human Factors Analysis and Classification System-HFACS. DOT/FAA/AM-00/7. U.S. Department of Transportation, Federal Aviation Administration, Washington, DC.

Sklet, S., 2004. Comparison of some selected methods for accident investigation. Journal of Hazardous Materials 111, 29-37.

Stanton, N.A., Rafferty, L.A., Blane, A., 2012. Human factors analysis of accidents in systems of systems. Journal of Battlefield Technology 15 (2), 23-30.

Steele, K., Pariès, J., 2006. The process of tailoring models for a priori safety and risk management for use within industry. In: Hollnagel, E., Rigaud, E. (Eds.), Second Resilience Engineering Symposium. 8-10 November 2006, Mines Paris.

Underwood, P., Waterson, P., 2012. A critical review of the STAMP, FRAM and Accimap systemic accident analysis models. In: Stanton, N.A. (Ed.), Advances in Human Aspects of Road and Rail Transportation. CRC Press, Boca Raton, pp. 385394.

Watson, H.A., 1961. Launch Control Safety Study. Section VII, vol. I. Bell Laboratories, Murray Hill.

Zio, E., Ferrario, E., 2013. A framework for the system-of-systems analysis of the risk for a safety-critical plant exposed to external events. Reliability Engineering \& System Safety 114, 114-125. 